\title{
Effect of the rise of a person's income on inequality
}

\author{
Rodolfo Hoffmann*
}

\begin{abstract}
If income distribution is unequal, the effect of a marginal increase in an income $x$ on inequality is an increasing function of $x$. The present paper analyses this function for several inequality measures. The income for which the effect changes sign is the relative poverty line. The value of this limit between the relatively poor and the relatively rich is computed for Brazil and five regions, in 1999, considering two types of income distribution: the income of economically active persons and per capita family income. The paper also analyses the effect that a marginal increase in all incomes equal to or greater than $x$ produces on inequality.
\end{abstract}

\section{Resumo}

Havendo desigualdade na distribuição da renda, o efeito de urn pequeno aumento em uma renda $x$ sobre a desigualdade é uma função crescente de $x$. Este trabalho analisa essa função para várias medidas de desigualdade. A renda para a qual aquele efeito muda de sinal é a linha de pobreza relativa. $O$ valor desse limite entre os relativamente pobres e os relativamente ricos é calculado para o Brasil e para 5 regiōes, em 1999, considerando, alternativamente, a distribuiçāo do rendimento das pessoas economicamente ativas e a distribuição do rendimento familiar per capita. Também é analisado o efeito, na desigualdade, de um acréscimo marginal em todas as rendas maiores ou iguais a $x$.

Key Words: Inequality, Income distribution, Relative poverty line .

JEL Code: C10, D31.

* Professor, Institute of Economics, UNICAMP. Study supported by CNPq. The author is grateful to the comments of Angela J. Corrêa, Angela A. Kageyama and Reynaldo Fernandes. The latter debated the paper at the 13th Brazilian Symposium of Econometrics, in December 2001.

Brazil ian Review of Econometrics Rio de Janeiro v.21, $\mathrm{n}^{\mathbf{0}} 2$, pp.237-262 Nov.2001 


\section{Introduction.}

Obviously, an increase in a rich person's income contributes to inequality, whereas an increase in a poor person's income has the opposite effect. Therefore, the effect of an income rise on inequality should be an increasing function of a person's income: it is negative for very low incomes, and positive for high ones. The present paper analyzes this function, showing how it is associated with the adopted inequality measure. It is important to know the value of the income for which the effect changes sign in order to find out the point from which tax incidence (income reduction) can contribute to reduce inequality or from which point an increment in income can cause inequality to grow. This income is the limit between the "relatively poor" and the "relatively rich", called relative poverty line or dividing line between the rich and the poor.

The second section deals with the formal definition of the effect of an income rise on the measure of inequality, showing the relationship with the effect of a regressive transfer of income and deducing the expressions for that effect on the major inequality measures. The third section shows how that effect behaves in some theoretical distributions, especially the lognormal distribution. In the fourth section, the results are applied to income distribution in Brazil, based on the Pesquisa Nacional por Amostra de Domiclios (PNAD) carried out in 1999. The fifth section analyses the effect that an increase in all incomes equal to or greater than a given value produces on inequality. The sixth section presents the main results of the study. 
2. The effect of an income rise on inequality.

Consider that $x_{i}$ is the income of a person in a population with $n$ people. consider that incomes are ordered such that

$$
x_{1} \leq x_{2} \leq \cdots \leq x_{h} \leq \cdots \leq x_{n}
$$

Let $I$ be the value of an inequality measure for this distribution.

Consider now that an increase $\theta$ is granted to the income of person $h$, which becomes $x_{h}+\theta$. If the new value of the inequality measure is indicated by $I_{*}$, the increase $\theta$ in $x_{h}$ will have caused the following variation in the inequality measure

$$
\Delta I=I_{*}-I
$$

This variation will usually be a function of $x_{h}$ and of $\theta$. To simplify the function and facilitate comparisons between inequality measures, the effect of the increase in income $x_{h}$ on inequality is defined as

$$
\delta=\lim _{\theta \rightarrow 0} \frac{\Delta I}{\theta}=\lim _{\theta \rightarrow 0} \frac{d I_{*}}{d \theta}
$$

Effect $\delta$ can also be obtained through the partial derivative of $I$ with respect to the income that receives the increase, that is,

$$
\delta=\frac{\partial I}{\partial x_{h}}
$$

A regressive transfer of income consists in subtracting an amount $\theta$ of $x_{h}$ and adding it to $x_{j}$, with $x_{j}>x_{h}$. Obviously, the effect $(\psi)$ of this regressive transfer on inequality measure $I$ equals the sum of 
the effects of the increase in $x_{j}$ and of the decrease in $x_{h}$. Indicating the effects of increases in $x_{h}$ and $x_{j}$, respectively by $\delta\left(x_{h}\right)$ and $\delta\left(x_{j}\right)$, the effect of the regressive transfer is

$$
\psi=\delta\left(x_{j}\right)-\delta\left(x_{h}\right), \text { with } x_{j}>x_{h}
$$

The Pigou-Dalton Transfer Principle establishes that an inequality measure should increase with a regressive transfer, that is, $\psi>0$. Therefore, if measure $I$ obeys the Pigou-Dalton Transfer Principle, we should have

$$
\delta\left(x_{j}\right)>\delta\left(x_{h}\right) \text { for } x_{j}>x_{h}
$$

This shows that effect $\delta\left(x_{h}\right)$ should be a monotonically increasing function of income $x_{h}$ for the inequality measure to obey the Pigou-Dalton Transfer Principle.

Let us see, first, how effect $\delta$ behaves if we adopt Theil's $L$ index as inequality measure. One way to calculate $L$ is

$$
L=-\frac{1}{n} \sum \ln \frac{x_{i}}{\mu}=\ln \mu-\frac{1}{n} \sum \ln x_{i}
$$

where $\mu$ is the average income (Hoffmann, 1998, p. 107).

After an increase $\theta$ in income $x_{h}$, the average income increases by $\theta / n$ and the inequality measure is

$$
L_{*}=\ln \left(\mu+\frac{\theta}{n}\right)-\frac{1}{n}\left[\sum_{i \neq h} \ln x_{i}+\ln \left(x_{h}+\theta\right)\right]
$$

Hence

$$
\frac{d L_{*}}{d \theta}=\frac{1}{n \mu+\theta}-\frac{1}{n\left(x_{h}+\theta\right)}
$$


So, for Theil's $L$ index, the effect of the increase in $x_{h}$ is

$$
\delta_{L}=\lim _{\theta \rightarrow 0} \frac{d L_{*}}{d \theta}=\frac{1}{n}\left(\frac{1}{\mu}-\frac{1}{x_{h}}\right)=\frac{1}{n \mu}\left(1-\frac{\mu}{x_{h}}\right)
$$

We observe that $\delta_{L}$ is an increasing function of $x_{h}$, which is negative for $x_{h}<\mu$ and positive for $x_{h}>\mu$.

Now observe how $\delta$ varies in function of $x_{h}$ in the case of Theil's $T$ index. This inequality measure can be defined as

$$
T=\frac{1}{n} \sum \frac{x_{i}}{\mu} \ln \frac{x_{i}}{\mu}=\frac{1}{n \mu} \sum x_{i} \ln x_{i}-\ln \mu
$$

After an increase $\theta$ in income $x_{h}$, the expression becomes

$$
T_{*}=\frac{1}{n \mu+\theta}\left[\sum_{i \neq h} x_{i} \ln x_{i}+\left(x_{h}+\theta\right) \ln \left(x_{h}+\theta\right)\right]-\ln \left(\mu+\frac{\theta}{n}\right)
$$

By deriving it and simplifying it, we obtain

$$
\frac{d T_{*}}{d \theta}=\frac{\ln \left(x_{h}+\theta\right)}{n \mu+\theta}-\frac{1}{(n \mu+\theta)^{2}}\left[\sum_{i \neq h} x_{i} \ln x_{i}+\left(x_{h}+\theta\right) \ln \left(x_{h}+\theta\right)\right]
$$

Then we find

$$
\delta_{T}=\lim _{\theta \rightarrow 0} \frac{d T_{*}}{d \theta}=\frac{1}{n \mu}\left(\ln x_{h}-\frac{1}{n \mu} \sum_{i=1}^{n} x_{i} \ln x_{i}\right.
$$

Recalling (7), we conclude that the effect of an increase in $x_{h}$ on theil's $T$ index is

$$
\delta_{T}=\frac{1}{n \mu}\left(\ln \frac{x_{h}}{\mu}-T\right)
$$


This effect is positive for $x_{h}>\mu e^{T}$. The larger the inequality, the higher the income of the favored person should be so that the increase enhances inequality.

Both $T$ and $L$ are special cases of the general measure (See Hoffmann, 1998, p.175)

$$
S=\frac{1}{\varepsilon(1-\varepsilon)}\left[1-\frac{1}{n} \sum\left(\frac{x_{i}}{\mu}\right)^{1-\varepsilon}\right]
$$

Theil's $T$ index is obtained through $\varepsilon \rightarrow 0$ while Theil's $L$ index is obtained through $\varepsilon \rightarrow 1$. For $\varepsilon=-1$, we observe that $2 S=C^{2}$, where $C$ is the coefficient of variation of incomes $x_{i}$.

Using a procedure similar to the one used for $L$ and $T$, we can deduce that the effect of an increase in $x_{h}$ on measure $S$ is

$$
\delta_{S}=\frac{1}{n \mu \varepsilon}\left[\frac{1}{n} \sum\left(\frac{x_{i}}{\mu}\right)^{1-\varepsilon}-\left(\frac{x_{h}}{\mu}\right)^{-\varepsilon}\right]
$$

or

$$
\delta_{S}=\frac{1}{n \mu \varepsilon}\left[1-S \varepsilon(1-\varepsilon)-\left(\frac{\mu}{x_{h}}\right)^{\varepsilon}\right]
$$

We verify that expression (6), which refers to Theil's $L$ index, is obtained from (12) by making $\varepsilon=1$ and that expression (9), which refers to Theil's $T$ index, is the limit of (12) when $\varepsilon \rightarrow 0$.

Note that effects $\delta_{L}, \delta_{T}$ and $\delta_{S}$ are null if we consider a perfectly equal distribution, that is, if we initially have $x_{i}=\mu$ for each $i$.

One of the formulas used to calculate the Gini coefficient is (Hoffmann, 1998, p. 41)

$$
G=\frac{2}{n^{2} \mu} \sum_{i=1}^{n} i x_{i}-1+\frac{-}{n}
$$




\section{Rodolfo Hoffmann}

Let us initially consider that an increase $\theta$ in $x_{h}$ does not change the income ordering of the $n$ persons. We will come back to this question later. If no reordering occurs after an increase $\theta$ in $x_{h}$, the expression for the Gini coefficient will be

$$
G_{*}=\frac{2}{n(n \mu+\theta)}\left[\sum_{i \neq h h} i x_{i}+h\left(x_{h}+\theta\right)\right]-\left(1+\frac{1}{n}\right)
$$

Hence

$$
\frac{d G_{*}}{d \theta}=\frac{2 h}{n(n \mu+\theta)}-\frac{2}{n(n \mu+\theta)^{2}}\left[\sum_{i \neq h} i x_{i}+h\left(x_{h}+\theta\right)\right]
$$

and

$$
\delta_{G}=\lim _{\theta \rightarrow 0} \frac{d G_{*}}{d \theta}=\frac{1}{n \mu}\left(\frac{2 h}{n}-\frac{2}{n^{2} \mu} \sum_{i=1}^{n} i x_{i}\right)
$$

Recalling (13), we conclude that the effect of an increase in $x_{h}$ on the Gini coefficient is

$$
\delta_{G}=\frac{1}{n \mu}\left[\frac{2 h}{n}-\left(G+1+\frac{1}{n}\right)\right]
$$

For a large $n$, we may disregard $\frac{1}{n}$ and then the effect becomes positive for

$$
\frac{h}{n}>\frac{G+1}{2}
$$

If, for instance, we have $G=0.6$, effect $\delta_{G}$ becomes positive for the increase in incomes greater than the $80^{\text {th }}$ percentile. 
Since effect $\delta_{G}$ is defined as a limit with $\theta$ tending to zero, we may admit that $\theta$ is quite small, so that having $x_{h+1}>x_{h}$ is enough for the increase $\theta$ not cause reordering. If there is a series of equal incomes, increase $\theta$ should be applied to the "last" in the series, so that we have $x_{h+1}>x_{h}$. It is interesting to consider the special case of perfectly equal distribution. In this case, the effect of an increase $\theta$ on an income may be obtained from (14) by $h=n$ and $G=0$ :

$$
\delta_{G}=\frac{1}{n \mu}\left(1-\frac{1}{n}\right)
$$

However, if a second income receives an increase $\theta$, the effect will be weaker. It is possible to prove that by starting with the perfectly equal distribution, the effect on the Gini coefficient of the $k^{\text {th }}$ successive increase $\theta$ in incomes with a previous $\mu$ value is

$$
\frac{1}{n \mu}\left(1-\frac{2 k-1}{n}\right)
$$

and that the aggregate effect of all $k$ increases is

$$
\frac{k}{n \mu}\left(1-\frac{k}{n}\right)
$$

As expected, the value of this last expression will be zero when $k=n$, that is, when all incomes receive an increase $\theta$.

Finally, we may observe that, when incomes differ, an increase that implies reordering always corresponds to a series of increases without reordering, according to the anonymity principle. 
3. The effect of an income rise on the inequality of continuous distributions.

For a continuous variable with distribution function $F(x)$, the effect of an increase in $x_{h}$ on the Gini coefficient may be obtained through proper adaptations of expression (14):

$$
\delta_{G}=\frac{1}{\mu}\left[2 F\left(x_{h}\right)-(G+1)\right]
$$

For other inequality measures analyzed, the expressions for the effect of an increase in $x_{h}$, in the case of a continuous distribution are

$$
\begin{gathered}
\delta_{L}=\frac{1}{\mu}\left(1-\frac{\mu}{x_{h}}\right)=\frac{1}{\mu}-\frac{1}{x_{h}} \\
\delta_{T}=\frac{1}{\mu}\left(\ln \frac{x_{h}}{\mu}-T\right) \\
\delta_{S}=\frac{1}{\mu \varepsilon}\left[1-S \varepsilon(1-\varepsilon)-\left(\frac{\mu}{x_{h}}\right)^{\varepsilon}\right]
\end{gathered}
$$

Note that only for the Gini coefficient the functional relationship between $\delta$ and $x_{h}$ depends on the form of the distribution.

We simply have to replace $\varepsilon$ with 1 in expression (19) in order to obtain expression (17). Expression (18) is the limit of (19) when $\varepsilon \rightarrow 0$.

For the sake of illustration, we are going to initially consider a uniform distribution at the interval between 0 and $b$. The probability density function is

$$
f(x)=\frac{1}{b},
$$


Effect of the rise of a person's income on inequality

the distribution function is

$$
F(x)=\frac{x}{b}
$$

$\mu=b / 2$, the Gini coefficient $(G)$ is $1 / 3, L=1-\ln 2$ and $T=$ $=\ln 2-0.5$. Note that measure $S$ for this uniform distribution, for $\varepsilon<2$, is

$$
S=\frac{1}{\varepsilon(1-\varepsilon)}\left(1-\frac{2^{1-\varepsilon}}{2-\varepsilon}\right)
$$

Replacing these results in expressions (16) through (19), we obtain

$$
\begin{gathered}
\delta_{G}=\frac{4}{b}\left(\frac{x_{h}}{b}-\frac{2}{3}\right) \\
\delta_{L}=\frac{2}{b}-\frac{1}{x_{h}} \\
\delta_{T}=\frac{2}{b}\left(\ln \frac{x_{h}}{b}+\frac{1}{2}\right) \\
\delta_{S}=\frac{2}{b \varepsilon}\left[\frac{2^{1-\varepsilon}}{2-\varepsilon}-\left(\frac{b}{2 x_{h}}\right)^{\varepsilon}\right] \text { for } \varepsilon<2
\end{gathered}
$$

Table 1 shows, for several inequality measures, the income value above which an increase in income causes inequality to grow, considering a uniform distribution at the interval between 0 and $b$. Note that, for measures in family $S$, this value decreases as parameter $\varepsilon$ increases. 


\section{Rodolfo Hoffmann}

\section{Table 1}

Value of $x_{h}$ from which an increase in income causes inequality to grow, for several inequality measures, in the case of a uniform distribution at the interval between 0 and $b$.

\begin{tabular}{lc}
\hline \multicolumn{1}{c}{ Inequality measure } & $x_{h}$ \\
\hline Gini coefficient $(G)$ & $\frac{2}{3} b=0.667 b$ \\
$S$ with $\varepsilon=-1$ (when $\left.2 S=C^{2}\right)$ & $\frac{2}{3} b=0.667 b$ \\
$S$ with $\varepsilon=-0.5$ & $0.64 b$ \\
Theil's $T$ index $(\varepsilon=0)$ & $e^{-0.5} b=0.6065 b$ \\
$S$ with $\varepsilon=0.5$ & $0.5625 b$ \\
Theil's $L$ index $(\varepsilon=1)$ & $0.5 b$ \\
\hline
\end{tabular}

Let us examine the lognormal distribution, admitting that the (neperian) logarithm of income $x$ has a normal distribution with mean $a$ and variance $v^{2}$. The mode, the median and the mean for $x$ are $^{1}$, respectively, $\exp \left(a-v^{2}\right), \exp (a)$ and

$$
\mu=\exp \left(a+0.5 v^{2}\right)
$$

If $\Phi$ is the standard normal distribution function, the Gini coefficient for the lognormal distribution is ${ }^{2}$

$$
G=2 \Phi\left(\frac{v}{\sqrt{2}}\right)-1
$$

Theil (1967, p. 97 and p. 127) showed that his two inequality measures for this distribution are

$$
T=L=\frac{v^{2}}{2}
$$

${ }^{1}$ See Aitchison and Brown, 1957, p.9.

${ }^{2}$ Same as, p.13. 
According to Cowell (1995, p. 142), measure $S$ for a lognormal distribution is ${ }^{3}$

$$
S=\frac{1}{\varepsilon^{2}-\varepsilon}\left\{\exp \left[\left(\varepsilon^{2}-\varepsilon\right) \frac{v^{2}}{2}\right]-1\right\}
$$

The results in (27) can be obtained by determining the limit of expression (28) for $\varepsilon$ tending to 0 or 1 .

From (18) and (25) we obtain for the lognormal distribution,

$$
\delta_{T}=\frac{1}{\mu}\left(\ln x_{h}-a-v^{2}\right)
$$

From (19) and (28), we obtain

$$
\delta_{S}=\frac{1}{\mu \varepsilon}\left\{\exp \left[\left(\varepsilon^{2}-\varepsilon\right) \frac{v^{2}}{2}\right]-\left(\frac{\mu}{x_{h}}\right)^{\varepsilon}\right\}
$$

For $\varepsilon=-1$, for instance, the expression will be

$$
\delta_{S}(\varepsilon=-1)=\frac{1}{\mu}\left[\frac{x_{h}}{\mu}-\exp \left(v^{2}\right)\right]
$$

4. Effect of the rise of a person's income on the inequality of the income distribution in Brazil.

To begin with, we analyze the effect of the increase of a person's income on inequality with regard to income distribution of economically active persons and, later, we do the same with the distribution of per capita family income.

\footnotetext{
${ }^{3}$ The formula presented by Cowell is slightly different, since he uses parameter $\theta=1-\epsilon$
} 
4.1 Income distribution of economically active persons.

According to data from PNAD 1999, the distribution of all income sources to economically active persons whose income was greater than zero presented the following characteristics:
a) mean: $R \$ 552.7$
b) median: $\mathrm{R} \$ 286$
c) Gini coefficient: 0.572
d) Theil's $T$ index: 0.665
e) Theil's $L$ index: 0.595

To facilitate the analysis of the effect that the rise of one person's income has on inequality, we are going to consider a lognormal distribution with parameters $a=-1.24$ and $v^{2}=1.28$. This distribution has characteristics that resemble those of the income distribution of EAP (economically active population) in Brazil in 1999 (in thousands of reais). We can observe that, recalling (25), (26) and (27), the median for this distribution is $\exp (a)=0.289$, the mean is 0.549 , $T=L=0.64$ and $G=0.576$.

Using (16), (17), (29) and (30), we can analyze how effect $\delta$ varies in function of income $x_{h}$ for the lognormal distribution similar to the income distribution per economically active person (not including those without income) in Brazil in 1999. Figure 1 shows the graph for the effect on the Gini coefficient, $T, L$ and on measure $S$ for $\varepsilon=0.5, e=-0.5$ and $\varepsilon=-1$. 
Effect of the rise of a person's income on inequality

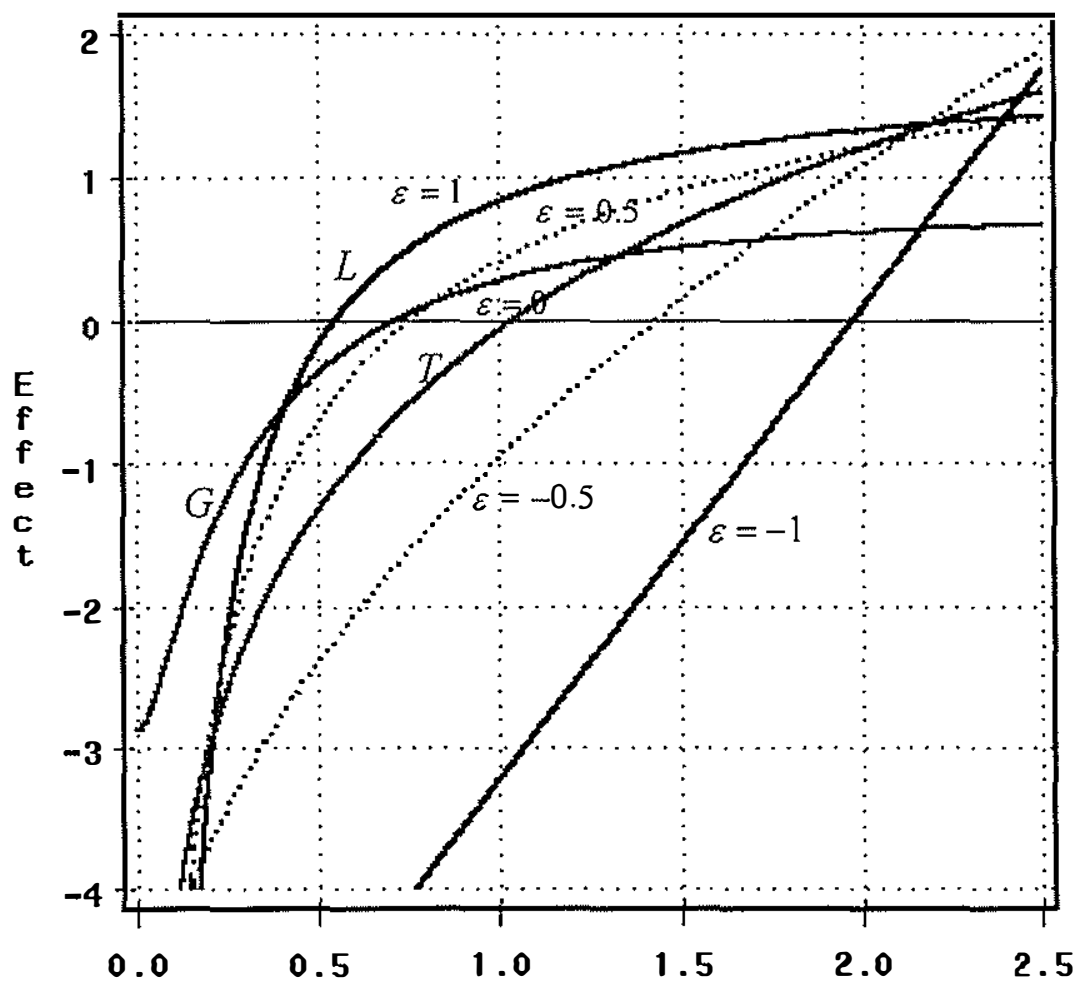

Income (R\$ 1,000 of September 1999)

Figure 1. Effect of the rise of one person's income on the inequality of income distribution of EAP with income, Brazil, 1999.

It is important to observe that the abscissa of the point at which there is a change of sign in the effect increases as parameter $\varepsilon$ decreases. Recall that Atkinson (1973) shows that $\varepsilon>0$ is a measure of the degree of inequality-aversion. Figure 1 shows that a higher $\varepsilon$ (higher inequality-aversion) implies lower values for the limit above which the increase of a person's income causes inequality to rise.

To better visualize how the results vary with $\varepsilon$, we consider the values of this parameter as -1 to 1 . However, the two most com- 
monly used $S$-type inequality measures are Theil's $T$ and $L$ indices, which respectively correspond to $\varepsilon=0$ and $\varepsilon=1$. When $\varepsilon=-1$, the $S$ measure is a monotonically increasing transformation of the coefficient of variation $\left(S=0.5 C^{2}\right)$, which is an inequality measure whose sensitivity to regressive transfers increases with the income level affected by transfers, that is, an inequality measure more sensitive to changes in the upper end of the income distribution. Since the concern with inequality is often associated with the struggle against poverty, it is sensible enough to prefer $S$-type inequality measures with $\varepsilon \geq 0$. Among the inequality measures that follow the PigouDalton Transfer Principle, the most commonly used are, of course, the Gini coefficient and Theil's measures ( $T$ and $L)$.

Table 2 shows the monthly income for which the effect $\delta$ changes sign, in $R \$ 1,000$, of September 1999, which is the month used as reference by PNAD. The first column shows the values obtained for the lognormal distribution with parameters $a=-1.24$ and $v^{2}=1.28$ (respectively, mean and variance of logarithms). The second column shows the values obtained directly from PNAD's individual data. Since the Gini coefficient obtained from these data is 0.572 , according to expression (14) the change of sign occurs at the $78.6^{\text {th }}$ percentile, which is $\mathrm{R} \$ 625$. For Theil's $L$ index, the change of sign in effect $\delta$ occurs at the distribution mean, which is approximately $\mathrm{R} \$ 553$. For Theil's $T$ index, the change of sign in $\delta$ occurs when the income of the economically active person is $\mathrm{R} \$ 1,075$. If we consider the set of these three inequality measures, we can observe that all of them decrease if any income below $\mathrm{R} \$ 553$ is increased, whereas all of them increase if any income greater than $R \$ 1,075$ is increased. 
Effect of the rise of a person's income on inequality

\section{Table 2}

Income for which the effect $\delta$ changes sign based on the inequality measure of EAP's income distribution (not including those without income) in Brazil, according to the data obtained from PNAD 1999.

Income ( $R \$ 1,000)$

Inequality measure

Lognormal distribution with

$a=-1.24$ and $v^{2}=1.28$

Directly considering the PNAD data

\begin{tabular}{lll}
\hline$G$ & $0.715^{*}$ & $0.625^{* *}$ \\
$L(\varepsilon=1)$ & $0.549(\operatorname{mean})$ & $0.553($ mean $)$ \\
$S$ with $\varepsilon=0.5$ & 0.756 & 0.758 \\
$T(\varepsilon=0)$ & 1.041 & 1.075 \\
$S$ with $\varepsilon=-0.5$ & 1.433 & 1.550 \\
$S$ with $\varepsilon=-1$ & 1.974 & 2.206 \\
\hline
\end{tabular}

"The $78.81^{\text {th }}$ percentile.

${ }^{* *}$ The $78.6^{t h}$ percentile.

By adopting the Gini coefficient as inequality measure, the limit between the "relatively poor" and the "relatively rich" in the economically active population of Brazil in 1999 (not including persons without income) is $R \$ 625$. Considering that the income registered by PNAD is an understatement of true income ${ }^{4}$, this limit is likely to reach nearly $R \$ 1,000$. Economically active persons with an income greater than $\mathrm{R} \$ 1,000$ in September 1999 were "relatively rich", as an increase in the income of any of them would cause the Gini coefficient to rise.

\footnotetext{
${ }^{4}$ Comparing data from PNAD 1995 with the per capita GDP of Brazilian states, Hoffmann (2001) shows that the level of understatement increases with the income value, exceeding $40 \%$ in some states.
} 


\section{Rodolfo Hoffmann}

Table 3 shows the values of incomes for five regions in Brazil, in which there is a change of sign in $\delta$, corresponding to the values that refer to Brazil in the last column of Table 2. As expected, the limits between the "relatively poor" and the "relatively rich" tend to increase with the average income for the region. This is evident in the case of Theil's $L$ index, when the limit is the average income itself. By adopting the Gini coefficient as inequality measure, we observe that the persons who are "relatively rich" in the state of São Paulo are those who earn more than $\mathrm{R} \$ 840$; however, in the Northeast, those who earn more than $\mathrm{R} \$ 350$ are already "relatively rich" within the region.

\section{Table 3}

Income (in $\mathrm{R} \$$ ) for which the effect $\delta$ changes sign based on the inequality measure of EAP's income distribution (not including those without income), in 5 regions of Brazil, according to the data obtained from PNAD 1999.

Region

Inequality measure

\begin{tabular}{lccccc} 
& Northeast & MG+ES+RJ & SP** & South & Midwest \\
\hline$G$ & 350 & 600 & 840 & 670 & 600 \\
$L(\varepsilon=1)$ & 334 & 550 & 777 & 595 & 577 \\
$S$ with $\varepsilon=0.5$ & 471 & 739 & 1,001 & 795 & 804 \\
$T(\varepsilon=0)$ & 717 & 1,037 & 1,325 & 1,100 & 1,190 \\
$S$ with $\varepsilon=-0.5$ & 1,140 & 1,510 & 1,775 & 1,545 & 1,841 \\
$S$ with $\varepsilon=-1$ & 1,750 & 2,244 & 2,346 & 2,127 & 2,876 \\
\hline
\end{tabular}

*MG $=$ State of Minas Gerais, ES=State of Espírito Santo and

$\mathrm{RJ}=$ State of Rio de Janeiro

* SP $=$ State of São Paulo 
Although the average income in the state of São Paulo is substantially higher than that in the midwest region, the incomes for which the effect $\delta$ changes sign for measure $S$ with $\varepsilon=-0.5$ and $\varepsilon=-1$ are higher in the midwest region. This occurs because these measures are very sensitive to changes in the upper end of the income distribution and due to the fact that inequality in the midwest region ( $G=0.581$ and $T=0.724$ ) is higher than in the state of São Paulo $(G=0.522$ and $T=0.534)$.

\subsection{Distribution of per capita family income.}

Consider now the distribution of per capita family income. According to PNAD 1999, this distribution presented the following characteristics:
a) mean: $R \$ 254.6$
b) median: $\mathrm{R} \$ 130$
c) Gini coefficient: 0.600
d) Theil's $T$ index: 0.723

If per capita incomes are measured in thousands of reais, a lognormal distribution with parameters $a=-2.06$ and $v^{2}=1.40$ has very similar characteristics: mean $=0.257$, median $=0.127, T=0.70$ and $G=0.597$. Figure 2 shows how effect $\delta$ varies, in this case, in function of per capita family income, for several inequality measures: The Gini coefficient $(G)$, Theil's $T$ and $L$ indices, and $S$ measure for $\varepsilon=0.5, \varepsilon=-0.5$ and $\varepsilon=-1$. 


\section{Rodolfo Hoffmann}

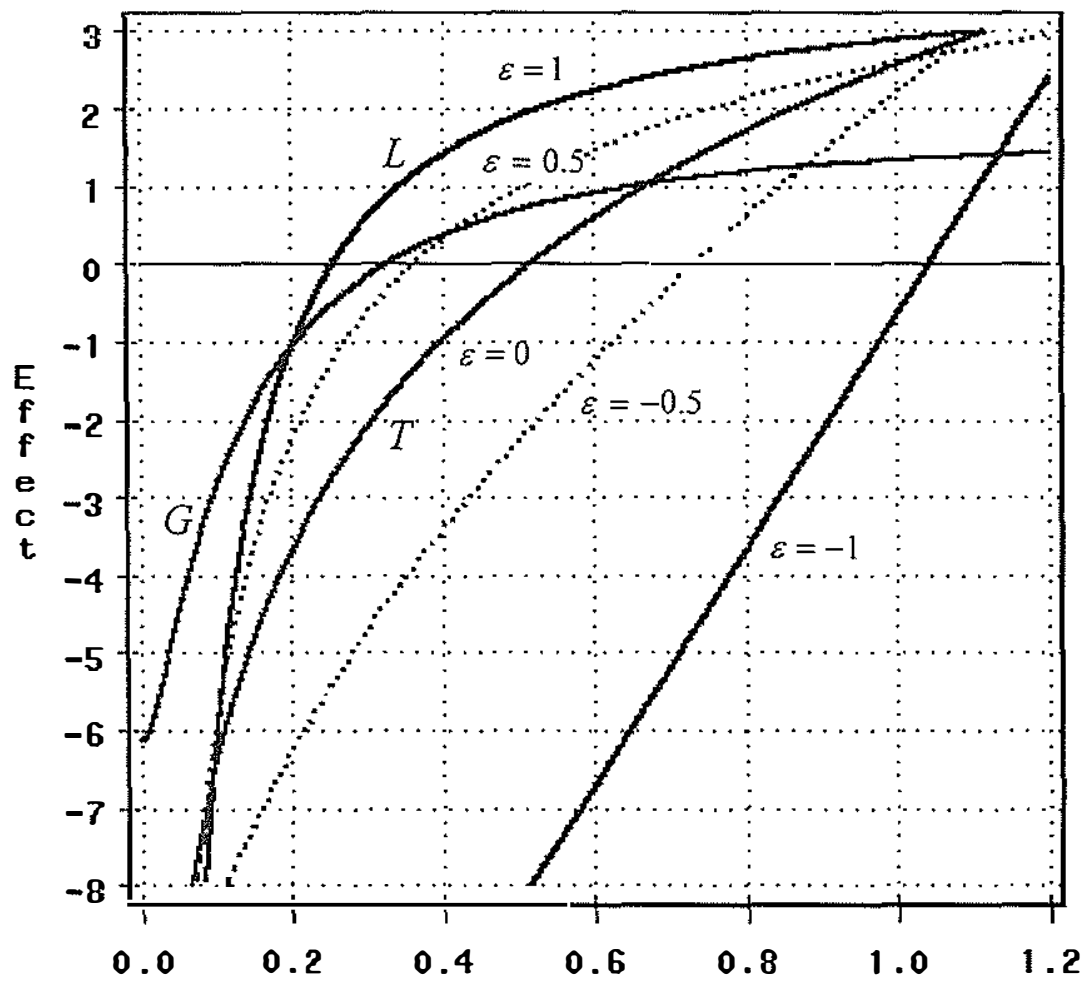

Per capita income (R\$ 1,000 of Sept.99)

Figure 2. Effect of the rise of one person's income on the inequality of per capita family income distribution, Brazil, 1999.

Table 4 shows the monthly per capita income for which the effect $\delta$ changes sign, in $R \$ 1,000$, of September 1999. The first column shows the values obtained for the lognormal distribution with parameters $a=-2.06$ and $v^{2}=1.40$. The second column shows the values directly obtained from PNAD data. By adopting the Gini coefficient as inequality measure, persons with per capita family income greater than $\mathrm{R} \$ 325$ are "relatively rich", since the increase in income of any of these persons would cause an increase in the Gini coefficient of the per capita family income distribution in Brazil. Considering an 
Effect of the rise of a person's income on inequality

understatement of incomes, that limit would increase from $\mathrm{R} \$ 325$ to approximately $\mathrm{R} \$ 500$ per capita.

\section{Table 4}

Income for which the effect $\delta$ changes sign, based on the inequality measure of per capita family income distribution in Brazil, according to PNAD 1999.

Per capita income ( $\mathrm{R} \$ 1,000)$

Inequality measure

Lognormal distribution with

Directly considering the

\begin{tabular}{lcc} 
& $a=-2.06$ and $v^{2}=1.40$ & PNAD data \\
\hline$G$ & $0.343^{*}$ & $0.325^{* *}$ \\
$L(\varepsilon=1)$ & 0.257 (mean $)$ & $0.255($ mean $)$ \\
$S$ with $\varepsilon=0.5$ & 0.364 & 0.367 \\
$T(\varepsilon=0)$ & 0.517 & 0.525 \\
$S$ with $\varepsilon=-0.5$ & 0.733 & 0.757 \\
$S$ with $\varepsilon=-1$ & 1.041 & 1.081 \\
\hline
\end{tabular}

"The $79.85^{\text {th }}$ percentile.

${ }^{* *}$ The $80^{t / 2}$ percentile.

Table 5 shows the limits between the "relatively poor" and the "relatively rich" in five regions of Brazil, considering several inequality measures of per capita family income distribution according to PNAD 1999.

If the Gini coefficient is adopted as inequality measure, the limit in the Northeast ( $\mathrm{R} \$ 162$ ) will be half the value for Brazil ( $\mathrm{R} \$ 325)$. In the state of São Paulo, the limit ( $R \$ 433)$ is $4 / 3$ of the limit for Brazil. In the richest region analyzed, the persons with per capita family income greater than $\mathrm{R} \$ 433$ are relatively rich, since an increase in the income of any of these persons would cause the Gini 
coefficient to grow. Considering an understatement of incomes in the PNAD, we may consider that the relative poverty line in this region is close to $R \$ 700$ per capita.

\section{Table 5}

Per capita income (in $\mathrm{R} \$$ ) for which the effect $\delta$ changes sign, based on the inequality measure of per capita family income distribution, in 5 regions of Brazil, according to PNAD 1999.

Region

Inequality measure

\begin{tabular}{lccccc} 
& Nort heast & MG+ES+RJ** & SP** & South & Midwest \\
\hline$G$ & 162 & 327 & 433 & 345 & 326 \\
$L(\varepsilon=1)$ & 141 & 274 & 368 & 290 & 274 \\
$S$ with $\varepsilon=0.5$ & 209 & 383 & 492 & 399 & 394 \\
$T(\varepsilon=0)$ & 321 & 540 & 654 & 548 & 578 \\
$S$ with $\varepsilon=-0.5$ & 509 & 784 & 879 & 762 & 879 \\
$S$ with $\varepsilon=-1$ & 777 & 1,159 & 1,173 & 1,052 & 1,357
\end{tabular}

"MG $=$ State of Minas Gerais, ES=State of Espirito Santo and RJ=State of Rio de Janei:

${ }^{*} \mathrm{SP}=$ State of São Paulo

5. Effect of the rise of all incomes equal to or greater than a given value on inequality .

Consider, again, the ordered set of incomes $x_{1} \leq x_{2} \leq \cdots \leq$ $x_{h} \leq \cdots \leq x_{n}$. Imagine that $I$ is the value of an inequality measure of this distribution. Let us admit an increase $\theta$ in all incomes from $x_{h}$ onwards and that after this increase, the inequality measure is $I_{\square}$. We define the effect of the increase as

$$
\Omega\left(x_{h}\right)=\lim _{\theta \rightarrow 0} \frac{I_{\square}-I}{\theta}=\lim _{\theta \rightarrow 0} \frac{d I_{\square}}{d \theta}
$$


Recalling the definition of effect $\left[\delta\left(x_{j}\right)\right]$ of an income rise, given at the beginning of section (2), we observe that ${ }^{5}$

$$
\Omega\left(x_{h}\right)=\sum_{i=h}^{n} \delta\left(x_{i}\right)
$$

A phenomenon like this occurs, for instance, if the income tax exemption limit is increased. If the initial exemption limit is $c_{0}$, the new limit is $c_{1}>c_{0}$ and the tax rate is $t$, the increase in the exemption limit will produce an increase equal to $\theta=t\left(c_{1}-c_{0}\right)$ in the available income of all persons with income equal to or greater than $c_{1}$. If we admit that $c_{1}$ is slightly greater than $c_{0}$, we may disregard the changes in the disposable incomes of those with an income between $c_{0}$ and $c_{1}$.

After the adoption of an inequality measure, let us consider $\lambda$ as the value of income for which the effect $\delta\left(x_{j}\right)$ changes sign. Looking at expression (33), it is evident that effect $\Omega\left(x_{h}\right)$ will be positive for an $x_{h}$ slightly lower than $\lambda$, provided that positive $\delta\left(x_{j}\right)$ compensate for negative $\delta\left(x_{j}\right)$. Nevertheless, there will always be a very low $x_{h}$ value that makes effect $\Omega\left(x_{h}\right)$ negative, since an increase $\theta$ in all incomes of a given population causes a decrease in inequality (unless this inequality is already equal to zero).

Expression (33) and the properties of effect $\delta\left(x_{j}\right)$ allow us to conclude that $\Omega\left(x_{h}\right)$ will be maximal when $x_{h}=\lambda$. For $x_{h}<\lambda$, negative $\delta\left(x_{j}\right)$ will be included, thus reducing the value of $\Omega\left(x_{h}\right)$.

\footnotetext{
${ }^{5}$ We should not forget that for the Gini coefficient, when incomes are exactly the same, it is necessary to take into consideration the sequence in which the increases are made, as discussed at the end of section 2 .
} 
For $x_{h}>\lambda$, positive $\delta\left(x_{j}\right)$ will not be included, also reducing the value of $\Omega\left(x_{h}\right)$.

According to expression (13), the Gini coefficient after the increases in incomes equal to or greater than $x_{h}$ is

$$
G_{\square}=\frac{2}{n[n \mu+(n-h+1) \theta]}\left[\sum_{i=1}^{h-1} i x_{i}+\sum_{i=h}^{n} i\left(x_{i}+\theta\right)\right]-\left(1+\frac{1}{n}\right)
$$

Deriving it with respect to $\theta$ and determining the limit for $\theta$ tending to zero, we obtain

$$
\Omega_{G}=\lim _{\theta \rightarrow 0} \frac{d G_{\square}}{d \theta}=\frac{n-h+1}{n \mu}\left[\frac{h}{n}-\left(G+\frac{1}{n}\right)\right]
$$

If, in this expression, $h=1$, we will obtain the effect of an increase in all incomes, which is $-G / \mu$. We may observe that, if there is inequality, an increase $\theta$ in all incomes causes the Gini coefficient to decrease from $G$ to $G \mu /(\mu+\theta)$.

Expression (35) shows that for a quite large $n$, effect $\Omega_{G}$ becomes positive from the $G^{t h}$ percentile onwards. For $G=0.6$, for example, effect $\Omega_{G}$ becomes positive after the $60^{t h}$ percentile of the income distribution.

Through expression (5), we may deduce that the effect of increases in all incomes equal to or greater than $x_{h}$ for Theil's $L$ index is

$$
\begin{aligned}
\Omega_{L} & =\frac{n-h+1}{n}\left(\frac{1}{\mu}-\frac{1}{n-h+1} \sum_{i=h}^{n} \frac{1}{x_{i}}\right)= \\
& =\frac{1}{n \mu}\left(n-h+1-\mu \sum_{i=h}^{n} \overline{x_{i}}\right.
\end{aligned}
$$

Brazilian Review of Econometrics 21 (2) November 2001 
Note that, in the first expression, the second term inside the parentheses is the inverse of the harmonic mean of incomes equal to or greater than $x_{h}$.

If all incomes have an increase $\theta$, we have $h=1$ and the effect is

$$
\Omega_{L}=\frac{1}{\mu}-\frac{1}{H}
$$

where $H$ is the harmonic mean of the $n$ incomes.

Through expression (7), for Theil's $T$ index, we have

$$
\begin{aligned}
\Omega_{T} & =\frac{n-h+1}{n \mu}\left(\frac{1}{n-h+1} \sum_{i=h}^{n} \ln \frac{x_{i}}{\mu}-T\right)= \\
& =\frac{1}{n \mu}\left[\sum_{i=h}^{n} \ln \frac{x_{i}}{\mu}-(n-h+1) T\right]
\end{aligned}
$$

For $h=1$ the effect is $\Omega_{T}=-(L+T) / \mu$.

Through expression (10), it is possible to infer that for inequality measure $S$, with $\varepsilon \neq 0$, we have

$$
\Omega_{S}=\frac{n-h+1}{n \mu \varepsilon}\left[\frac{1}{n} \sum_{i=1}^{n}\left(\frac{x_{i}}{\mu}\right)^{1-\varepsilon}-\frac{1}{n-h+1} \sum_{i=h}^{n}\left(\frac{x_{i}}{\mu}\right)^{-\varepsilon}\right]
$$

Note that (36) is the particular case of (38) when $\varepsilon=1$.

By examining PNAD 1999 data regarding all income sources for economically active persons with positive value for that income, we observe that the value for which the effect $\Omega$ changes sign is $R \$ 290$ for Theil's $L$ index, $\mathrm{R} \$ 336$ for the Gini coefficient, and $\mathrm{R} \$ 500$ for 
Theil's $T$ index. It is important to remember that for the same distribution, the change of sign in effect $\delta$ (or maximum effect $\Omega$ ) occurs when the income is respectively $R \$ 553, R \$ 625$ and $R \$ 1,075$ (see Table 2).

\section{Conclusions.}

This paper defines and analyzes the effect that an income rise produces on inequality. When inequality is present, this effect is negative for the relatively poor and positive for the relatively rich. Income $(\lambda)$ for which the effect changes sign is the relative poverty line, that is, the dividing line between the relatively poor and the relatively rich. If we want to divide an income distribution into only two strata, it would be reasonable to adopt income $\lambda$ as the dividing line between the rich and the poor.

By adopting the Gini coefficient as inequality measure and by considering PNAD 1999 data, limit $\lambda$ is $R \$ 625$ for the income per economically active person (not including those without income) and is $\mathrm{R} \$ 325$ for per capita family income. Considering that incomes are understated in PNAD, the correct value for these limits between the relatively poor and the relatively rich in Brazil should be close to $R \$ 1,000$ in the case of income per economically active person and $\mathrm{R} \$ 500$ in the case of per capita family income.

In addition, the effect of an increase in all incomes equal to or greater than a given value $x_{h}$ on inequality is also analyzed, showing that this effect is maximal for $x_{h}=\lambda$. This should be considered when establishing the limit of income tax exemption, if one wants to reduce inequality. 


\section{Effect of the rise of a person's income on inequality}

Submitted in January 2002. Revised in March 2002.

\section{References}

Aitchison, J. \& J. A. C. Brown 1957. The lognormal distribution, with special reference to its uses in economics. London, Cambridge University Press.

Atkinson, A. B. 1973. On the measurement of inequality. In Atkinson, A.B. (org.) Wealth, Income and Inequality 46-68. Harmondsworth, Penguin Education.

Cowell, Frank A. 1995. Measuring inequality. Second Edition. London, Prentice Hall/Harvester Wheatsheaf.

Hoffmann, Rodolfo 1998. Distribuição de renda: medidas de desigualdade e pobreza. São Paulo, Editora da Universidade de São Paulo.

Hoffmann, Rodolfo 2001. Income distribution in Brazil and the regional and sectoral contrasts. In Guilhoto, J. J. M. e Hewings, G. J. D. (org.) Structure and structural change in the Brazilian economy. Aldeersshort, Ashgate.

Theil, Henri 1967. Economics and information theory. Amsterdam, North-Holland. 